\title{
Clinical study of hemodynamic changes during extraction in controlled hypertensive patients
}

\author{
Francisco-Javier Silvestre ${ }^{1}$, Isabel Salvador-Martínez ${ }^{2}$, Daniel Bautista ${ }^{3}$, Javier Silvestre-Rangil ${ }^{4}$
}

\author{
${ }^{1}$ Assistant Professor, Department of Stomatology, Valencia University Dental School. Head of the Stomatology Unit, Dr. Peset \\ University Hospital, Valencia \\ ${ }^{2}$ Collaborating dental surgeon, Stomatology Unit, Dr. Peset University Hospital, Valencia \\ ${ }^{3}$ Staff physician, Department of Preventive Medicine, Dr. Peset University Hospital, Valencia (Spain) \\ ${ }^{4}$ Dental surgeon in private practice
}

\section{Correspondence:}

Unidad de Estomatología,

Hospital Universitario Dr. Peset (Consultas externas),

Juan de Garay s/n,

46017 Valencia (Spain)

francisco.silvestre@uv.es

Received: $12 / 04 / 2010$

Accepted: 27/06/2010

Silvestre FJ, Salvador-Martínez I, Bautista D, Silvestre-Rangil J. Clinical study of hemodynamic changes during extraction in controlled hypertensive patients. Med Oral Patol Oral Cir Bucal. 2011 May 1;16 (3):e354-8. http://www.medicinaoral.com/medoralfree01/v16i3/medoralv16i3p354.pdf

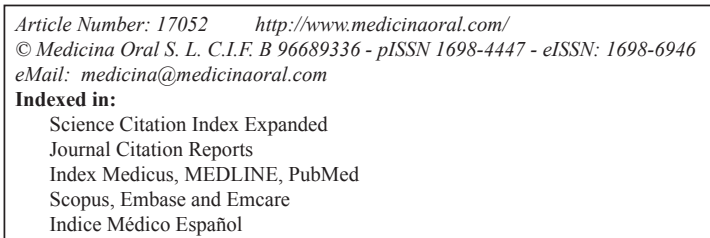

\begin{abstract}
Objective: To evaluate the efficacy and safety of the vasoconstrictor used in local anesthesia during dental extraction in controlled hypertensive patients.

Study Design: A prospective observational study was carried out in hypertensive patients $(n=97)$ with a mean age of $60.45 \pm 9.60$ years. The following parameters were monitored at three different timepoints (before the procedure, 3 minutes after local anesthesia infiltration, and 3 minutes after the operation): blood pressure (diastolic and systolic), heart rate, and oxygen saturation. Anesthesia (1-3 carpules) was provided in the form of articaine with $4 \%$ epinephrine as vasoconstrictor in one group, while another group received $3 \%$ mepivacaine without vasoconstrictor.

Results: All patients presented primary hypertension ( $\mathrm{n}=97)$ (grade I in $57.7 \%$ of the cases and grade II in $42.3 \%$ ). The most widely used antihypertensive drugs were angiotensin II receptor antagonists (ARA II). The only significant differences observed corresponded to systolic blood pressure measured before and after dental extraction in the group of hypertensive patients anesthetized with vasoconstrictor.

Conclusions: In procedures such as dental extraction, no significant hemodynamic changes in well controlled hypertensive patients are seen attributable to anesthetic use with a vasoconstrictor, when fewer than three local anesthetic carpules are administered.
\end{abstract}

Key words: Arterial hypertension, local anesthesia, vasoconstrictor, hemodynamic changes. 


\section{Introduction}

Local anesthetics reversibly block nerve conduction, inhibiting excitation of the myelinated and unmyelinated nerve fibers, slowing the velocity of the process in the depolarization phase, and reducing sodium ion influx. The local anesthetics most often used in dental practice include lidocaine, articaine and mepivacaine. These drugs are normally used in combination with a vasoconstrictor, with the purpose of slowing systemic absorption of the anesthetic - thus prolonging its action and the intensity of block. The use of a vasoconstrictor also increases safety, because lower anesthetic doses are needed, thereby contributing to lessen toxicity. In addition, a certain degree of ischemia is maintained, which facilitates hemostatic action and lessens bleeding (1). The most commonly used vasoconstrictors are epinephrine (adrenalin) and the norepinephrine (noradrenalin). These drugs act upon the alpha-adrenergic receptors of the vascular smooth muscle, causing vasoconstriction of the arterioles and venules of the local microcirculation. While epinephrine exerts its maximum action three minutes after injection, and the effect persists for about 30 minutes, it can cause adverse effects upon the central nervous and cardiovascular systems. Sung et al. (2) found that the administration of progressive doses of epinephrine at concentrations lower than those used in dental practice gives rise to increases in myocardial yield and oxygen consumption.

On the other hand, it is known that pain during dental treatment can trigger endogenous catecholamine release, which in turn can give rise to hemodynamic changes, such as increases in blood pressure and heart rate, and may even produce arrhythmias. Some authors (3) have reported significant increases $(5-12 \mathrm{mmHg})$ in systolic blood pressure in patients subjected to root scaling and planing using anesthesia with a vasoconstrictor.

There has been controversy regarding the use of epinephrine with local anesthetic solutions in patients with a history of cardiovascular problems, though at present the application of local anesthesia with a vasoconstrictor appears to be safe in avoiding patient pain and discomfort during dental treatment $(4,5)$.

The present study evaluates the safety and efficacy of two different local anesthetics (articaine and mepivacaine), with vasoconstrictor (VC) and without vasoconstrictor (WVC), in controlled hypertensive patients.

\section{Material and Methods}

An observational study was made of the hemodynamic constants of controlled hypertensive patients subjected to dental extraction. The study sample consisted of 97 adults seen in the Stomatology Unit (Dr. Peset University Hospital, Valencia, Spain) during the year 2009 for dental extraction. There were 64 females and 33 males, with a mean age of $60.45 \pm 9.60$ years (range $34-87$ ). A prior clinical history was compiled, a clinical examination was carried out, and a panoramic X-ray study was requested to evaluate buccodental health.

The patients were monitored for diastolic blood pressure (DBP) and systolic blood pressure (SBP), and pulsioximetry was used to record heart rate (HR) and oxygen saturation ( $\mathrm{SpO} 2)$. These hemodynamic parameters were recorded at three different timepoints: before the start of the procedure, three minutes after local anesthesia infiltration, and again three minutes after completing the surgical procedure.

The following inclusion criteria were established: hypertension controlled with antihypertensive medication; a maximum SBP of $139 \mathrm{mmHg}$, and a maximum DBP of $89 \mathrm{mmHg}$. Likewise, the patients were required to show very little anxiety or fear of extraction. All patients were informed of the purpose of the study, and signed consent was obtained in all cases.

Dental extraction was carried out in a relaxed atmosphere, with no anxiolytic premedication. On the day of the extraction the patients had a light breakfast and were instructed to take their usual medication at that time. The consumption of alcohol or coffee, and smoking, were to be avoided from the night before.

Blood pressure (BP) was measured with an electronic sphygmomanometer $\left(\mathrm{OMRON}^{\circledR}\right.$ Automatic Blood Pressure Moit no. 3). In the case of atrial fibrillation, a mercury sphygmomanometer was used. The cuff was placed on the right arm with the patient sitting in the dental chair.

Pulsioximetry was carried out with the Fingertip pulse Oximeter pm-50 ${ }^{\circledR}$, applied to the left index finger, which was required to be clean and free of nail varnish.

Infiltrating or regional (for lower molar extractions) local anesthesia was provided in the form of $4 \%$ articaine with epinephrine 1:200,000, injecting the anesthetic slowly and aspirating with an auto-aspirating syringe (Aspijet $^{\circledR}$, INIBSA). In all cases it was confirmed that the anesthetic solution was not directly injected into the bloodstream. A maximum of three anesthetic carpules were injected according to need (only one patient requiring 3 carpules). In the patients subjected to anesthesia without a vasoconstrictor (WVC), 3\% mepivacaine was administered under the same conditions as in the patients with vasoconstrictor (VC).

A single tooth was removed in each patients: 34 anterior sector teeth (35\%), 27 premolars $(27.83 \%)$ and 37 molars $(38.14 \%)$-including erupted third molars. For all sectors (anterior, premolars and molars) there were 45 right-side teeth $(46.39 \%)$ and 52 left-side teeth $(53.60 \%)$.

The indications for dental extraction were caries in 70 cases, periodontitis in one case, and combined caries and periodontitis in 26 cases. 


\section{Results}

The 97 patients included in the study presented a mean height of $169.94 \pm 8.42 \mathrm{~cm}$ and a mean body weight of $66.70 \pm 8.48 \mathrm{~kg}$ (range $60-95 \mathrm{~kg}$ ). All had been diagnosed with primary hypertension. A little over half of the patients $(57.7 \%)$ presented grade I hypertension, while 41 had grade II hypertension (42.3\%). None of the study subjects had grade III hypertension (Table 1).

The patients used antihypertensive medication - in $49.5 \%$ of the cases $(n=48)$ in combination with other drugs indicated for other diseases. The most commonly used antihypertensive drugs were angiotensin II receptor antagonists (ARA II), while $10.3 \%(n=10)$ were receiving calcium antagonists.
Most of the patients (76.3\%) had some other disease apart from hypertension, while 23 presented hypertension only $(23.7 \%)$. The most common comorbidities were ischemic heart disease, stroke and type 2 diabetes mellitus. Dyslipidemia was confirmed by the laboratory tests in 27 patients. As regards toxic habits, 31 patients were smokers (32\%) and 66 non-smokers (68\%). There was only one regular consumer of alcohol. A quarter of the study sample $(21.6 \%)$ was overweight.

In 21 cases $(21.6 \%)$, anesthesia for dental extraction involved no vasoconstrictor, while epinephrine was used in 76 cases (78.4\%). As regards the number of anesthetic carpules used, one was required in 42 cases $(43.3 \%)$, two in 55 cases $(56.7 \%)$, and three in only one patient.

Table 1. Diastolic and systolic blood pressure values and their relationship to dental treatment.

\begin{tabular}{|c|c|c|c|c|}
\hline & Systolic & Diastolic & Follow up & Dental treatment \\
\hline Normal & $<130$ & $<85$ & 2 years & Unrestricted \\
\hline Normal high & $130-139$ & $85-95$ & 1 year & Unrestricted \\
\hline \multicolumn{5}{|l|}{ Hypertension: } \\
\hline Grade I (mild) & $140-159$ & $90-99$ & 2 months & Unrestricted \\
\hline Grade II (moderate) & $160-179$ & $100-119$ & 1 month & Unrestricted \\
\hline Grade III (severe) & $180-209$ & $110-119$ & 1 week & $\begin{array}{l}\text { Emergency treatment avoiding asoconstrictor } \\
\text { Palliative treatment }\end{array}$ \\
\hline Grade IV (very severe) & $>210$ & $>120$ & $\begin{array}{l}\text { Refer to physician } \\
\text { immediately }\end{array}$ & Avoid vasoconstrictor \\
\hline
\end{tabular}

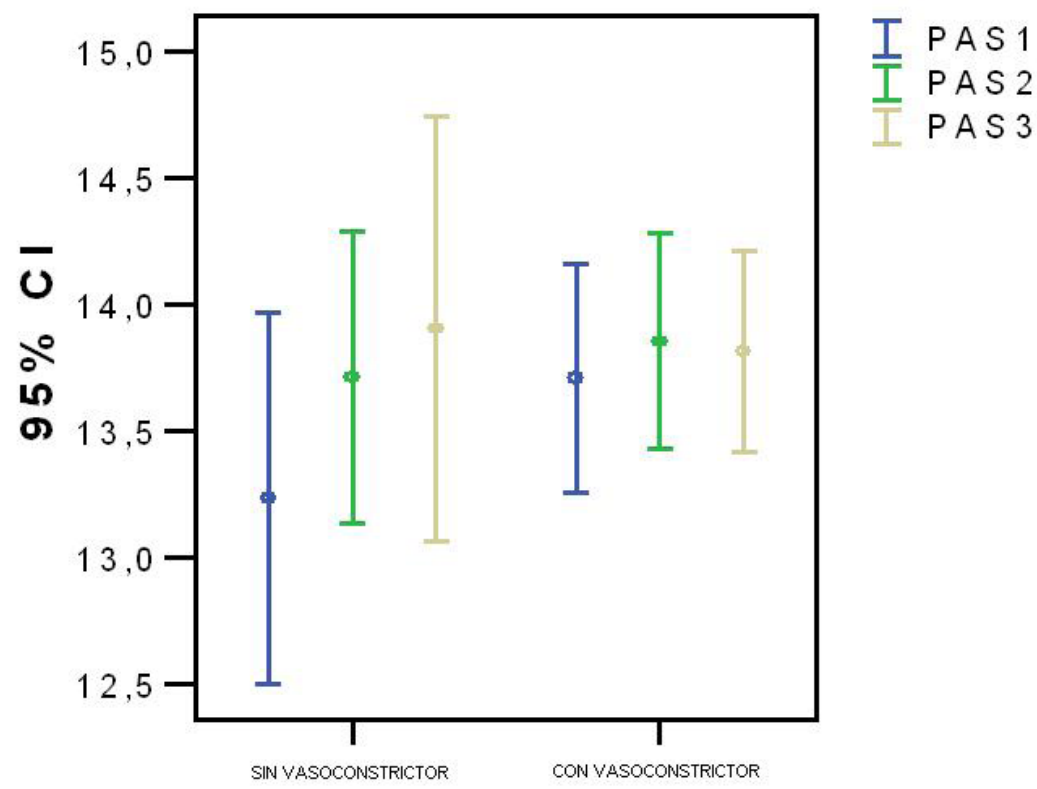

Fig. 1. Differences in mean systolic blood pressure (SBP) among the patients subjected to anesthetic injection without vasoconstrictor (WVC), at the three monitoring timepoints (SBP1, SBP2 and SBP3), with comparison versus the group without vasoconstrictor (VC). 


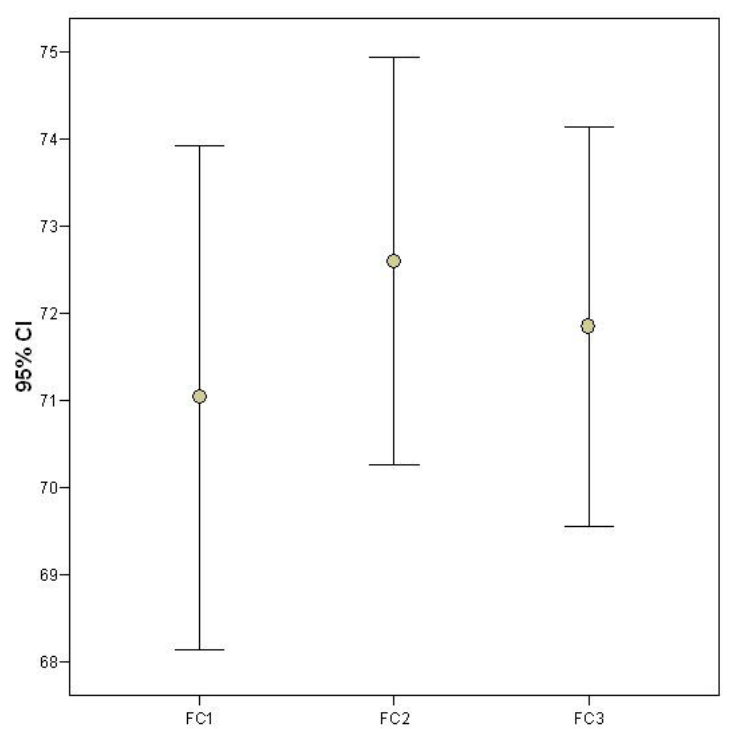

Fig. 2. Differences in heart rate (HR) among the patients subjected to anesthetic injection with vasoconstrictor (VC), at the three monitoring timepoints (HR1, HR2 and HR3).

Analysis of the global patient series (with and without vasoconstrictor) revealed no significant results at any of the three timepoints for the different study variables, i.e., DBP, SBP, HR and $\mathrm{SpO} 2$.

On evaluating the associations between variables at the three timepoints during dental extraction in the group of patients subjected to local anesthesia without vasoconstrictor (WVC), the only significant difference observed corresponded to SBP before (SBP1) and after extraction (SBP3) $(\mathrm{t}=-2.09 \mathrm{p}=0.049)$ (Fig. 1). In contrast, no differences were observed between the DBP values at the three monitoring timepoints (DBP1, DBP2 and DBP3).

In the case of the patients subjected to local anesthesia with vasoconstrictor (VC), the only change observed corresponded to heart rate before the procedure (HR1) and three minutes after anesthetic injection (HR2), though the difference only tended towards statistical significance $(t=-1.93 \mathrm{p}=0.056)$. In this context, both HR1 and heart rate at the end of the procedure (HR3) were lower than HR2 (Fig. 2).

The patients requiring less than two anesthetic carpules likewise showed a nonsignificant change in SBP between the first and third monitoring timepoints (i.e., SBP1 and SBP3) $(t=-1.94 \mathrm{p}=0.058)$. Lastly, the patients requiring two or more anesthetic carpules showed a nonsignificant change in heart rate between the first and second monitoring timepoints (HR1 and HR2) $(t=-1.95$ $\mathrm{p}=0.056$ ).

\section{Discussion}

Many hemodynamic studies have been made in patients subjected to local anesthetic injection with a vasoconstrictor (6-9). Some have been in subjects without a history of disease - no significant changes having been recorded in either blood pressure (systolic and diastolic) or heart rate. However, some authors have suggested that such changes are dependent upon the injected vasoconstrictor dose (10). In this context, it is clear that important variations are to be expected if the injection technique is not performed carefully and the solution is accidentally injected into a blood vessel (11).

On the other hand, catecholamines can give rise to clinically relevant interactions with other administered drug substances such as beta-blockers, tricyclic antidepressants, monoamine oxidase inhibitors (MAOIs) and certain sympathomimetics such as cocaine (12).

Dionne et al. (13) found that after the administration of $5.4 \mathrm{ml}$ of $2 \%$ lidocaine with epinephrine 1:100,000, taking care to avoid intravascular injection, the heart rate was increased in $19 \%$ of the cases, and cardiac output in up to $30 \%$. According to Silvestre et al. (14), the fact of using or not using a vasoconstrictor with the local anesthetic solution exerts no effect upon blood pressure in normotensive patients - though a certain increase in systolic blood pressure (SBP) was noted at the moment of tooth extraction and at the end of the procedure. This was attributed to increased patient anxiety during extraction, taking into account that the difference was comparatively greater between SBP at the start of the procedure and at the actual moment of extraction.

Fellows et al. (15), using intravenous injections of epinephrine (3.5 pg in one minute), recorded a 30\% increase in heart rate (HR), though the values returned to baseline levels after 15 minutes.

Some studies have suggested that while epinephrine injected as a vasoconstrictor is associated with transient effects in normotensive patients, hemodynamic complications could develop in uncontrolled hypertensive subjects, with possible cardiovascular accidents (16) though such problems would be related to the dose of vasoconstrictor administered, and to the local anesthetic used (10). In contrast, in the present study we recorded no changes in the hypertensive patients administered a vasoconstrictor. The only observation worth mentioning was an increase in mean SBP (more reactive) between before and after the surgical procedure among the patients not exposed to vasoconstrictor (WVC). This could be more closely related to patient anxiety or discomfort, as has already been seen in healthy individuals (14).

Likewise, Laragnoit et al. (3) reported no increases in heart rate or blood pressure in patients with heart disease during dental treatment with local anesthesia plus a vasoconstrictor. Neves et al. (5), in patients with 
a history of ischemic heart disease during restorative dental treatment, recorded small increases in systolic blood pressure, in coincidence with our own findings. However, they documented no significant differences in heart rate, blood pressure or the appearance of arrhythmias according to whether a vasoconstrictor was used or not.

The present study was designed to evaluate changes in three hemodynamic parameters (blood pressure, heart rate and $\mathrm{SpO} 2$ ) measured at three different timepoints during a routine dental procedure (tooth extraction), in a series of controlled hypertensive patients. No significant changes were observed in any of the study parameters. The patients subjected to local anesthesia with a vasoconstrictor showed a behavior similar to that observed in an earlier study by our group in patients without hypertension (14).

\section{References}

References with links to Crossref - DOI

1. Moore PA, Doll B, Delie RA, Hersh EV, Korostoff J, Johnson S, et al. Hemostatic and anesthetic efficacy of $4 \%$ articaine $\mathrm{HCl}$ with 1:200,000 epinephrine and $4 \%$ articaine $\mathrm{HCl}$ with $1: 100,000$ epinephrine when administered intraorally for periodontal surgery. J Periodontol. 2007;78:247-53.

2. Sung BH, Robinson C, Thadani U, Lee R, Wilson MF. Effects of 1-epinephrine on hemodynamics and cardiac function in coronary disease: dose-response studies. Clin Pharmacol Ther. 1988;43:308 16.

3. Laragnoit AB, Neves RS, Neves IL, Vieira JE. Locoregional anesthesia for dental treatment in cardiac patients: a comparative study of $2 \%$ plain lidocaine and $2 \%$ lidocaine with epinephrine $(1: 100,000)$. Clinics (Sao Paulo). 2009;64:177-82.

4. Neves RS, Neves IL, Giorgi DM, Grupi CJ, César LA, Hueb W, et al. Effects of epinephrine in local dental anesthesia in patients with coronary artery disease. Arq Bras Cardiol. 2007;88:545-51.

5. Elad S, Admon D, Kedmi M, Naveh E, Benzki E, Ayalon S, et al. The cardiovascular effect of local anesthesia with articaine plus 1:200,000 adrenalin versus lidocaine plus 1:100,000 adrenalin in medically compromised cardiac patients: a prospective, randomized, double blinded study. Oral Surg Oral Med Oral Pathol Oral Radiol Endod. 2008;105:725-30

6. Viana AM, Campos AC, Morlin MT, Chin VK. Plasma catecholamine concentrations and hemodynamic responses to vasoconstrictor during conventional or Gow-Gates mandibular anesthesia. Oral Surg Oral Med Oral Pathol Oral Radiol Endod. 2005;100:415-9.

7. Cáceres MT, Ludovice AC, Brito FS, Darrieux FC, Neves RS, Scanavacca MI, et al. Effect of local anesthetics with and without vasoconstrictor agent in patients with ventricular arrhythmias. Arq Bras Cardiol. 2008;91:128-33, 142-7.

8. Meechan JG, Parry G, Rattray DT, Thomason JM. Effects of dental local anaesthetics in cardiac transplant recipients. Br Dent J. 2002;192:161-3.

9. Kameyama K, Watanabe S, Kano T, Kusukawa J. Effects of nasal application of an epinephrine and lidocaine mixture on the hemodynamics and nasal mucosa in oral and maxillofacial surgery. J Oral Maxillofac Surg. 2008;66:2226-32.

10. Pérusse R, Goulet JP, Turcotte JY. Contraindications to vasoconstrictors in dentistry: Part I. Cardiovascular diseases. Oral Surg Oral Med Oral Pathol. 1992 ;74:679-86.

11. Delgado-Molina E, Tamarit-Borrás M, Berini-Aytés L, Gay-Escoda C. Evaluation and comparison of 2 needle models in terms of blood aspiration during truncal block of the inferior alveolar nerve. $\mathrm{J}$ Oral Maxillofac Surg. 2003;61:1011-5.

12. Wahl MJ, Brown RS. Dentistry's wonder drugs: local anesthetics and vasoconstrictors. Gen Dent. 2010;58:114-23.
13. Dionne RA, Goldstein DS, Wirdzek PR. Effects of diazepam premedication and epinephrine-containing local anesthetic on cardiovascular and plasma catecholamine responses to oral surgery. Anesth Analg. 1984;63:640-6.

14. Silvestre FJ, Verdú MJ, Sanchís JM, Grau D, Peñarrocha M. Effects of vasoconstrictors in dentistry upon systolic and diastolic arterial pressure. Med Oral. 2001;6:57-63.

15. Fellows IW, Bennett T, MacDonald IA. The effect of adrenaline upon cardiovascular and metabolic functions in man. Clin Sci (Lond). 1985;69:215-22.

16. Pérusse R, Goulet JP, Turcotte JY. Contraindications to vasoconstrictors in dentistry: Part II. Hyperthyroidism, diabetes, sulfite sensitivity, cortico-dependent asthma, and pheochromocytoma. Oral Surg Oral Med Oral Pathol. 1992;74:687-91. 